\title{
Web 2.0 and Medical Physics
}

\author{
Marius Treutwein
}

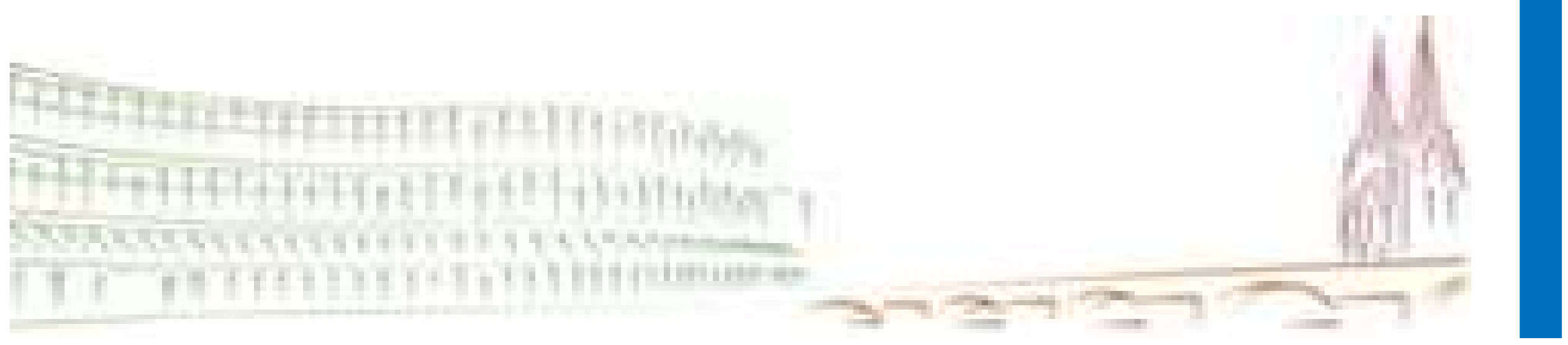




\section{What is Web 2.0?}

- O'Reilly Media 2004

- Name of a conference

- No version number

- Life Software

- No clear definition

- New Way using the Internet

- Web browser

- Users add value (codevelopers) 


\section{Applications and Services}

\section{Online shopping and auction website}

ebay

- Sell or buy

- Hardware

- Software

- Machines

- Parts
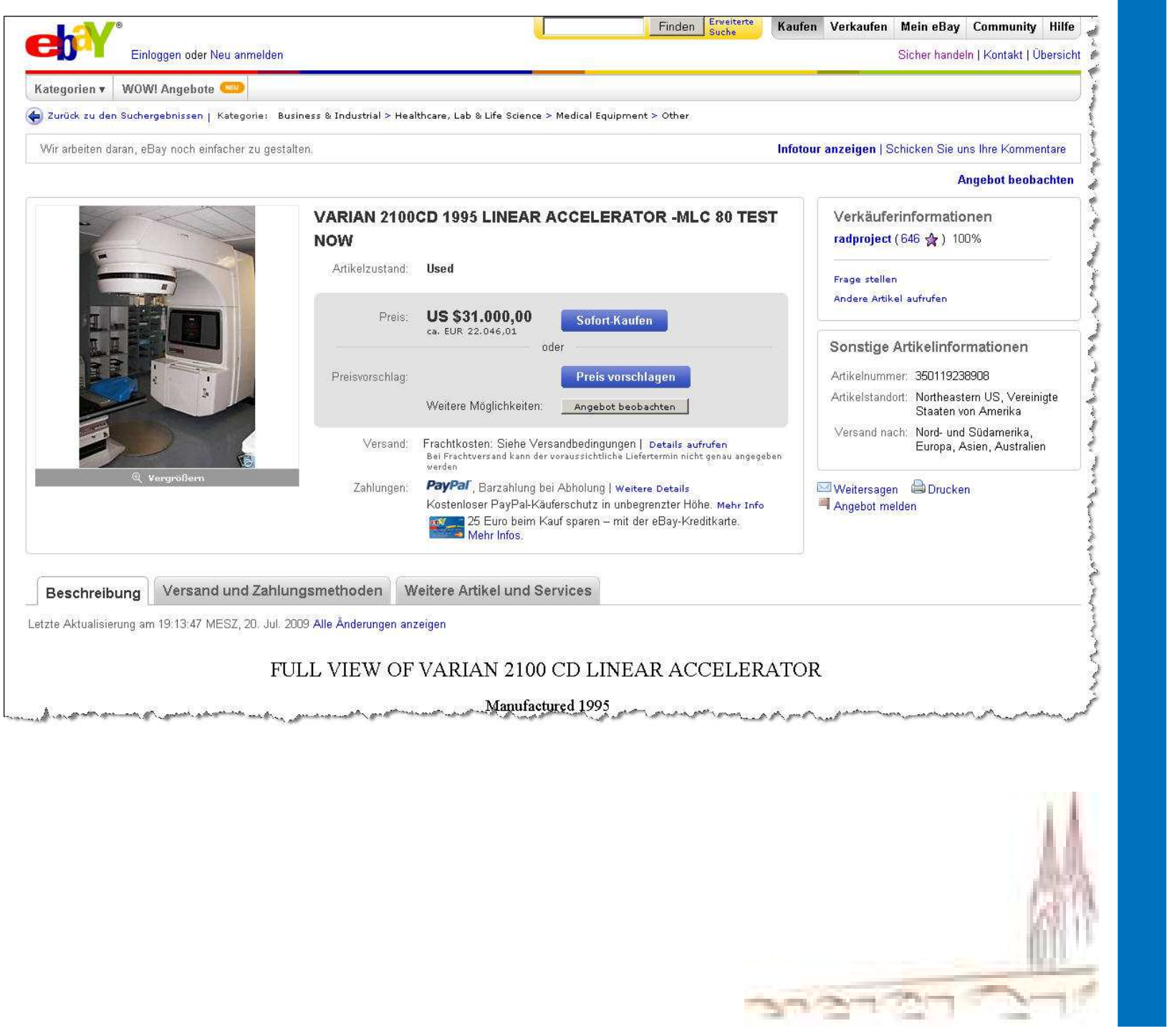


\section{Applications and Services}

\section{Encyclopaedias}

\section{Wikipedia}

- Participation

- Different Languages

- Picture and photo sharing

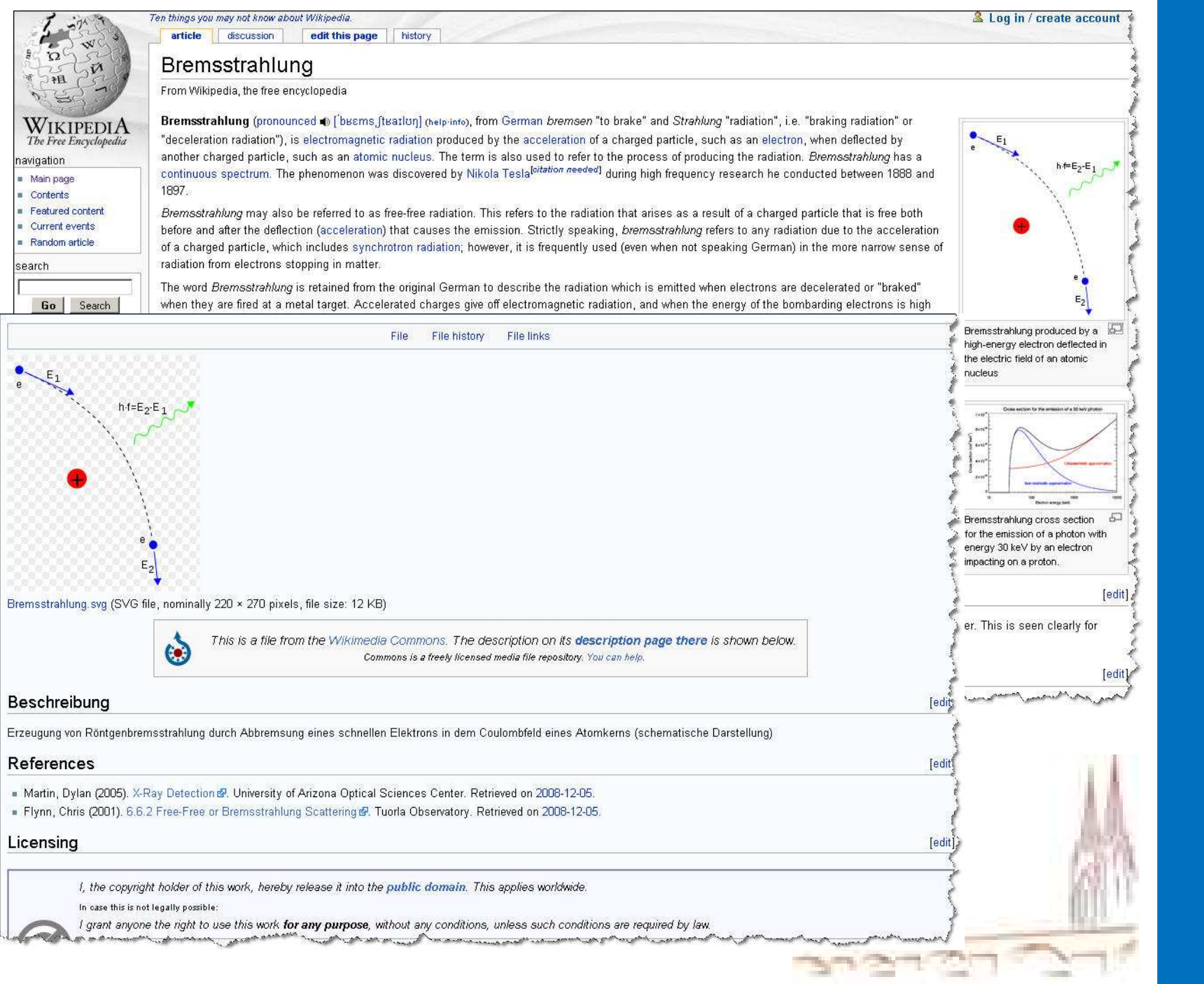




\section{Applications and Services}

\section{Mailing Lists}

- Mail program or Browser

- Database

- User Groups

- Regional

- Applicational

- Manufactural

$-\ldots$
Mailing Lists

The following mailing lists and web sites may be of interest to those in the radiation sciences. With mailing lists the privately. You will automatically receive instructions on how to unsubscribe after you subscribe to the list.

The AAPM Mailing Lists

The AAPM supports a number of official mailing lists for announcements, solicitation of member feedback and member and have your emal address on his in the memberhip drectory. The contact for posting to this list is the ther of its working groups.

A number of AAPM Regional Chapters also have their own mailing lists, some hosted by the AAPM, others hosted elsewhere. Some are unmoderated two-way discussion lists and are used for announcing chapter meetings and discussing chapter issues. AAPM chapter members may or may not be automatically subscribed depending on their chapter's mode of operating the list. Contact the Chapter President for the details of a given list.

Members of the American medical physics community seeking a national two-way list to discuss organizational or national issues may use MedPhysUSA without regard to membership in any particular organization.

Diagnostic Imaging Medical Physicists List (DXIMGMEDPHYS)

To subscribe, simply send the following text in the body of a message (not subjectl) to listserv@ermes. gwu. edu subscribe Name-of-the-list Your-First-Name Your-Last-Name

example: subscribe DXIMGMEDPHYS John Doe

Please note that your message cannot contain any other text, such as your signature file. Any other text is interpreted as a command, the LISTSERV server will return errors.

The American Medical Physics Mailing List (MedPhysUSA)

MedphySUSA provides an unmoderated two-way forum for issues that have limited interest outside of the USA and that would be inappropriate or inconsiderate to send to physicists worldwide via Global MedPhys. Topics may include government reimbursement, state and federal regs, certifying boards, job postings, local and regiona meeting announcements, etc. However everyone, regardless of location, is welcome to subscribe. Global MedPhys and MedPhySUSA subsciptchs are completely independent of each other even though they come from the same

subscribe MedPhysusa firstname lastname

without punctuation, degrees, certifications, military rank, etc, to listserv@lists.wayne.edu

For example send

address from the email address where you wish to receive the email.

The subject field is unimportant, only the text of the message is read by the Listserv software.

Subscription options and list archives are available at lists.wayne.edu/archives/medphysusa.html.

The Global Medical Physics Mailing List (MedPhys)

http://www.aapm.org/links/medphys/ 


\section{Applications and Services}

\section{Web Forums}

- http://www.medphysfiles.com

- http://www.advancedphysics.o rg/forum/

- http://www.radiotherapy.com/

- PW: fletcher

- http://www.strahlentherapieforum.de/index.php

- http://www.otpusergroup.de/forum/

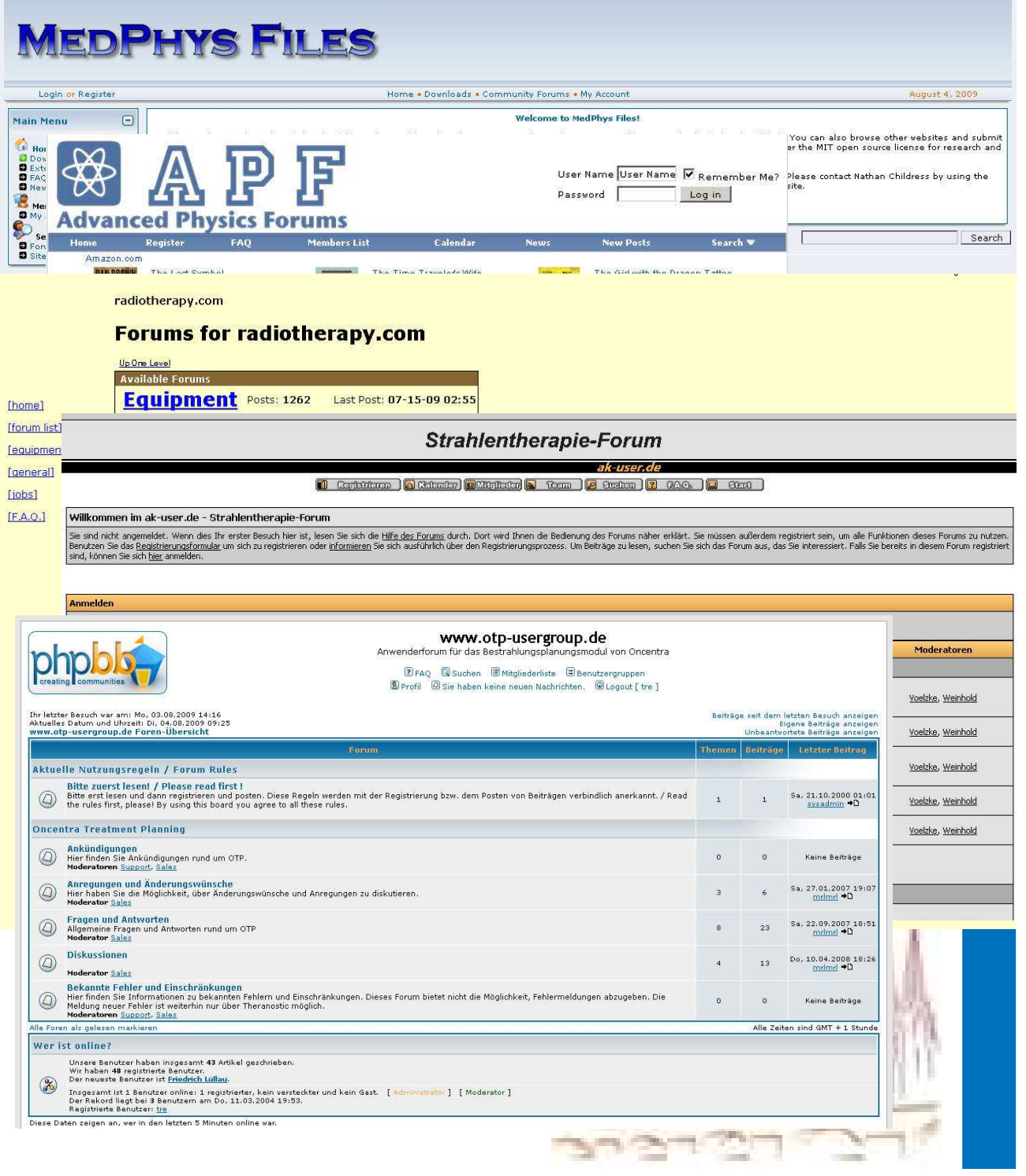




\section{Applications and Services}

\section{Journals}

- Online is not sufficient

- Peer Review

- Filter

- Open peer review

- Nature Trial 2006

- Open Website

- User Comments

- Only 5\% of Authors agreed

- Less than half of them got comments

1. (1) http:/3wwww. nature.com/nature/peerreview/faq, httml

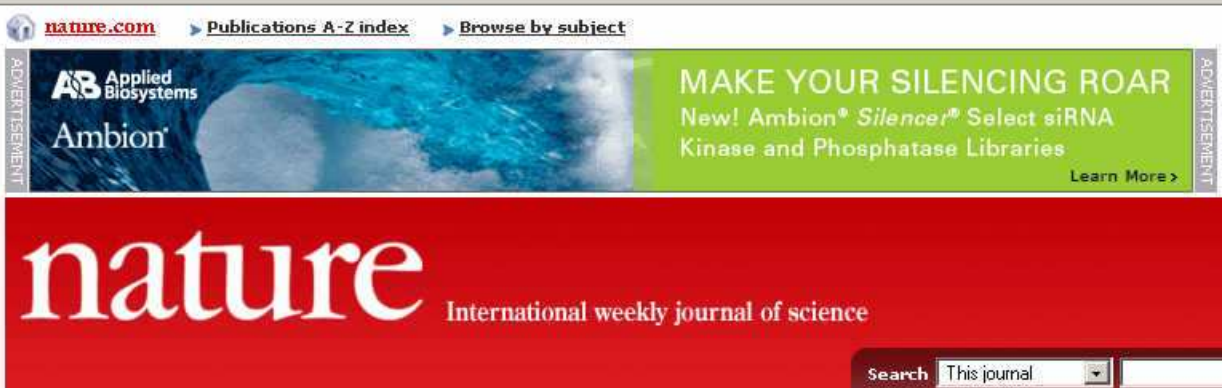

Journal home $>$ Web focuses $>$ Peer Review

Journal home

Nature Peer Review Trial: Frequently Asked Questions (FAQ)

Advance online

publication

Current issue

In June 2006, for about 3 months, Nature is undertaking a trial of one type of

peer review. This trial is continuing in parallel with the usual peer review process,

and will allow the editors to assess the value of soliciting comments from

Nature News

Archive

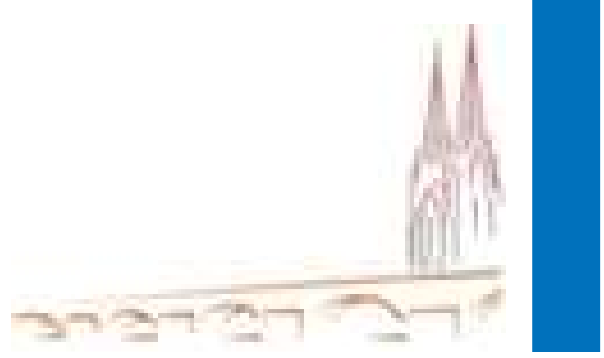




\section{Applications and Services}

\section{Others}

- Blogs

- http://penscience.wordpress.com/

- Online Bookmark Collections

- http://delicious.com

- Tagging

- Foto Sharing Services

- Tagging

- Licenses

- Video Sharing Services

- Interviews

- Documentations

- Teaching Videos, Lectures

- Product Presentations 


\section{Usage}

- Ebay

- USA

- Wikipedia

- Mailing Lists

- Bookmark Collections

- Foto- and Video sharing

- Forums

- Blogs

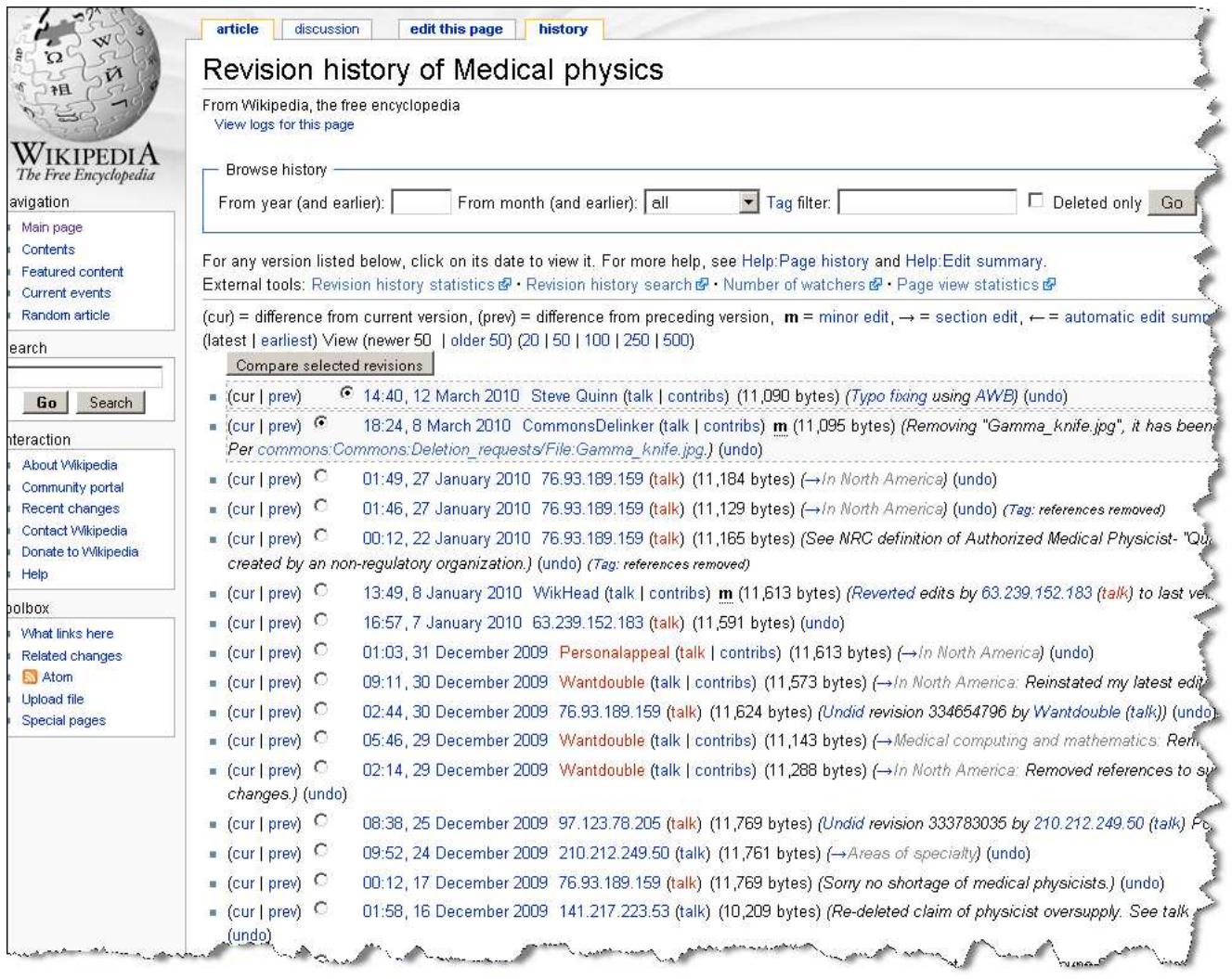

- Journals

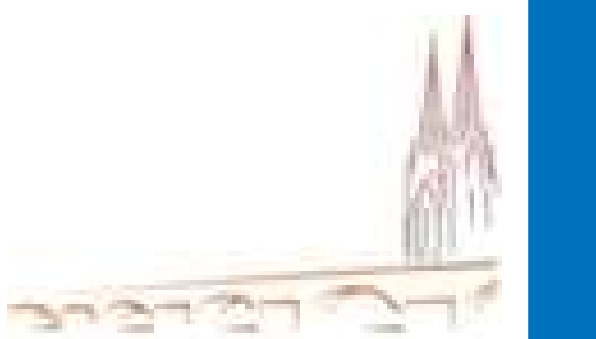




\section{Discussion}

- All well accepted applications are not dedicated to medical physics.

- Some applications are hard to find.

- Forums:

- For many web forums there are competing mailing lists.

- For some web forums the target group might be too small.

- Regular user meetings and service support might help in many cases.

- Blogs:

- Time consuming

- Enjoyment? ${ }^{1}$

- Journals

- There is no Web 2.0 journal.

- Fear for loosing results to a competitor. 


\section{Conclusion}

- Improvement of keywords in the header of Websites.

- There is still the chance for more offers . 